
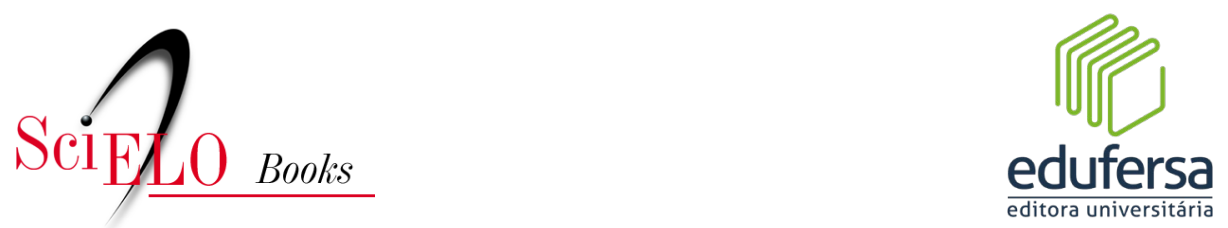

\title{
Parte I - Cultura e Cidadania 2 - O Movimento negro rural e a Comunidade Quilombola do Jatobá: a luta pelo reconhecimento
}

Rosimeiry Florêncio de Queiroz Rodrigues

Maria Santos

João Pedro Rodrigues de Queiroz

\section{SciELO Books / SciELO Livros / SciELO Libros}

RODRIGUES, R. F. Q., SANTOS, M., and QUEIROZ, J. P. R. O Movimento negro rural e a Comunidade Quilombola do Jatobá: a luta pelo reconhecimento. In: OLIVEIRA, A. M., SILVA, L. R., and FALCÃO, M. L., eds. Sociedade e cultura no Rio Grande do Norte: diálogos interdisciplinares [online]. Mossoró: EdUFERSA, 2021, pp. 37-59. ISBN: 978-65-87108-24-7. https://doi.org/10.7476/9786587108582.0003.

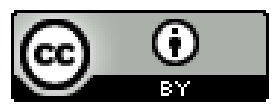

All the contents of this work, except where otherwise noted, is licensed under a Creative Commons Attribution 4.0 International license.

Todo o conteúdo deste trabalho, exceto quando houver ressalva, é publicado sob a licença Creative Commons Atribição 4.0.

Todo el contenido de esta obra, excepto donde se indique lo contrario, está bajo licencia de la licencia Creative Commons Reconocimento 4.0. 


\section{SciELO Books / SciELO Livros / SciELO Libros}

RODRIGUES, R. F. Q., SANTOS, M., and QUEIROZ, J. P. R. O Movimento negro rural e a Comunidade Quilombola do Jatobá: a luta pelo reconhecimento. In: OLIVEIRA, A. M., SILVA, L. R., and FALCÃO, M. L., ed. Sociedade e cultura no Rio Grande do Norte: diálogos interdisciplinares [online]. Mossoró: EdUFERSA, 2021, pp. 37-59. ISBN: 978-65-87108-24-7. https://doi.org/10.7476/9786587108582.0003.

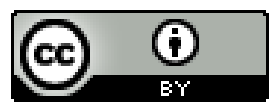

All the contents of this work, except where otherwise noted, is licensed under a Creative Commons Attribution 4.0 International license.

Todo o conteúdo deste trabalho, exceto quando houver ressalva, é publicado sob a licença Creative Commons Atribição 4.0.

Todo el contenido de esta obra, excepto donde se indique lo contrario, está bajo licencia de la licencia Creative Commons Reconocimento 4.0. 


\title{
(1) O MOVIMENTO NEGRO RURAL E A COMUNIDADE QUILOMBOLA DO JATOBÁ: A LUTA PELO RECONHECIMENTO ${ }^{2}$
}

\author{
Rosimeiry Florêncio de Queiroz Rodrigues \\ Maria Santos \\ João Pedro Rodrigues de Queiroz
}

\subsection{Palavras Iniciais}

O movimento negro rural ganha expressividade em sua organização na década de 1980, quando passa a reivindicar do poder público o reconhecimento territorial e a concessão da titulação coletiva de suas terras. Muito embora assegurada constitucionalmente, a concessão da titulação coletiva não tem se constituído num processo fácil para os interessados. Na verdade, tamanhas foram as dificuldades criadas pelos sucessivos governos, sobretudo, o de Fernando Henrique Cardoso (1995-2002), que a concretização desse direito se tornou um fardo

2 Esse texto comporta fragmentos da dissertação de mestrado de Rosimeiry Florêncio de Queiroz Rodrigues. O estudo etnográfico foi desenvolvido durante o curso de mestrado em Ciências Sociais e Humanas, ano de 2014, com uso das técnicas da pesquisa bibliográfica e de campo, além da utilização da observação participante e realização de entrevistas 
para muitos grupos. Questões como omissão legislativa, indefinição de competência quanto ao órgão responsável pela condução dos processos de titulação coletiva, inexistência de critérios que definam comunidades como quilombolas e embargos financeiros sempre foram apontados como os principais problemas enfrentados por esses grupos étnicos para a implementação de seu direito.

O processo de titulação coletiva das terras da comunidade negra do Jatobá ${ }^{3}$, situada no município de Patu, no estado do Rio Grande do Norte/RN, não pode ser compreendido dissociado desse contexto nacional de luta. A comunidade quilombola do Jatobá ${ }^{4}$ integra um conjunto de comunidades negras rurais que, com base no art. 68 do Ato das Disposições Constitucionais Transitórias (ADCT), estão requerendo o reconhecimento, demarcação e titulação coletiva das terras que ocupam, ou daquelas que, por motivo alheio à sua vontade, foram privados. Por isso, o reconhecimento da territorialidade dessa comunidade deve ser pensado como mais uma conquista do movimento negro na luta pela igualdade social no Brasil.

Pensando nisso, neste texto, nosso objetivo é abordar o reconhecimento da territorialidade da comunidade quilombola do Jatobá como uma conquista do movimento negro na luta pela igualdade social no Brasil. Além do mais, contribuir com os estudos sobre comunidades negras rurais, em especial do Estado do Rio Grande do Norte/RN, que conta atualmente com 30 comunidades remanescentes de quilombos certificadas pela Fundação Cultural Palmares ${ }^{5}$.

3 A comunidade negra do sítio Jatobá localiza-se na mesorregião oeste do Estado do Rio Grande do Norte/RN, situando-se a $10 \mathrm{~km}$ da sede do município de Patu, tendo como única via de acesso à comunidade uma estrada de barro, à margem da antiga estrada de ferro, que finda no município de Caraúbas.

4 Neste trabalho, utilizamos alternadamente as expressões "comunidade negra do Jatobá" e "comunidade quilombola do Jatobá" referindo-se ao mesmo grupo étnico.

5 Informação disponível em: http://www.palmares.gov.br/sites/mapa/ crqs-estados/crqs-rn-21022020.pdf. Acesso em: 01 maio 2020. As informações desse quadro foram atualizadas até 21 de fev. de 2020. 


\subsection{De mãos dadas na luta por direitos}

Para pensar o processo que discute a regularização do território ${ }^{6}$ quilombola do Jatobá, é necessário situar a ação da comunidade negra do Jatobá num contexto de atuação política do movimento negro no Brasil. Para tanto, faz-se necessário mostrar a atuação desse movimento na busca pela implementação do art. 68 do ADCT, que dispõe sobre o direito ao reconhecimento e titulação coletiva das terras dos "remanescentes de quilombo".

O movimento negro ${ }^{7}$ no Brasil desponta como nova ${ }^{8}$ estratégia de combate à desigualdade social e seus efeitos. Nesse propósito, vai-se destacar em sua capacidade de organização de movimentos sociais. Ressalta-se, contudo, que não há uma uniformidade nesse movimento, mas, ao contrário, comporta uma pluralidade de associações e organizações e estas, por sua vez, possuem pontos que as aproximam e que as distanciam, conforme as experiências e particularidades de cada grupo. Para efeito de estudo, centramos a divisão desse movimento

6 Segundo Raffestin (1993), o conceito de território pode ser entendido como o espaço apropriado pelo homem e sobre o qual estabelece relações de poder. Difere, portanto da noção de espaço. Este volta-se para a terra em seu estado original, precedendo qualquer ação humana, enquanto aquele reveste-se numa produção a partir do uso do espaço pelo homem.

7 O marco do movimento negro, enquanto organização social, remonta à década de 1930, com destaque na atuação da Frente Negra brasileira, entre os anos de 1931 e 1937, e do Movimento Negro Unificado de 1978.

8 O negro fez uso de várias formas de resistência ao regime escravocrata, que podem ser expressas desde as mais radicais, o suicídio e homicídio de seus senhores, até suas manifestações na cultura brasileira a exemplo da dança, religião, arte e língua. 
em duas bases: a urbana e a rural ${ }^{9}$. Josilene Brandão ${ }^{10}$, integrante do movimento negro rural do Maranhão, em entrevista concedida ao Centro de Pesquisa e Documentação em história contemporânea da Fundação Getúlio Vargas, explicou que, em seu âmbito interno, o movimento quilombola constitui-se na vertente rural do movimento negro.

Quando a gente fala "movimento negro", ele engloba tanto o rural quanto o urbano. E o movimento quilombola é uma vertente no meio rural. O movimento negro urbano foi que constituiu as organizações, e tem muitas instituições, em nível nacional ou mais local, que contribuíram para esse mosaico do movimento negro brasileiro. O movimento quilombola faz parte dessa história dentro do viés da ruralidade. Qual a diferença disso tudo? São as práticas: a forma de organização e a institucionalidade do movimento são diferentes. 0 que nos junta é mesma condição de desigualdade racial. Ou seja, estamos no mesmo contexto de desigualdade e discriminação, viemos de uma mesma origem. Alguns negros se fixaram no meio rural na construção dos quilombos, outros negros estão no meio urbano e se organizaram nos seus diferentes grupos sociais e

9 Como exemplo da organização negra urbana contemporânea, pode-se destacar a Coordenação Nacional de Entidades Negras (Conem) e a União de Negros pela Igualdade (Unegro). No âmbito rural, o Movimento Quilombola (MQ), que aparece como uma nova forma de organização e mobilização negra após 1988, com reivindicação centrada na questão fundiária. Dentre suas agências está a Coordenação Nacional de Articulação das Comunidades Negras Rurais Quilombolas - Conaq. As três organizações - a Coordenação Nacional de Entidades Negras (Conem), a União de Negros pela Igualdade (Unegro) e o Movimento Quilombola - apresentam como ponto comum a causa negra. Porém, no que pertine à institucionalidade, a Unegro dedica-se à defesa da igualdade racial; a Conem a uma representação geral de todas as entidades negras a nível nacional; e o Movimento Quilombola volta as suas discussões para a questão do direito à terra do negro residente em comunidades rurais.

10 No ano da entrevista concedida ao CPDOC, em 2005, integrava a Coordenação Nacional de Quilombos (CONAQ) e cursava Jornalismo. 
institucionais. No entanto, o movimento de quilombolas tem um diferencial, porque se está discutindo em torno de uma territorialidade. Não quer dizer que o movimento negro urbano não tenha essa luta. Acontece que ela é diferente, porque você está em diferentes lugares no meio urbano, em diferentes instituições, lutando pelo rompimento com o racismo e com a discriminação racial, e tem muitas formas e muitas causas, muitos debates e muitos assuntos que são tratados em torno disso (ALBERTI; PEREIRA, 2007, p. 310, grifo nosso).

Percebe-se, portanto, que o movimento negro, em seu âmbito interno, pode ser compreendido a partir de duas vertentes: a urbana e a rural, consistindo o movimento quilombola na vertente rural do movimento negro. Contudo acentuamos que até a década de 1980, não se falava nesse segmento.

Apesar de o movimento quilombola centrar-se nas comunidades negras rurais, isso não significa que não existam quilombos urbanos ${ }^{11}$, tampouco que as comunidades negras rurais não recebam assistência do movimento negro urbano. Na verdade, as duas agendas somam-se em torno de um problema comum: a desigualdade racial no Brasil. Esse problema, de certa forma, provocou o fortalecimento das entidades, organizações e movimento negro, enquanto mecanismo de luta na defesa dos direitos da população negra, expandindo suas reivindicações aos planos nacional e internacional ${ }^{12}$.

11 Um exemplo é a comunidade quilombola de Moita Verde, localizada na cidade de Parnamirim/RN. A regularização dessa comunidade, juntamente com a dos sítios Sobrado, Arrojado, Pega e Lajes, todos de Portalegre/RN, foi iniciada de ofício pelo Incra, ou seja, sem solicitação prévia das comunidades. (Informação fornecida via e-mail por Thiago Leite de Barros, do setor de regularização de territórios quilombolas).

12 No âmbito internacional, podemos destacar como instrumentos de promoção dos direitos dessa minoria, a Declaração Universal dos Direitos Humanos, de 1948; os Pactos Internacionais dos Direitos Civis e Políticos e dos Direitos Econômicos, Sociais e Culturais de 1966; e do Programa de Ação de Durban (DDPA), de 2001. Este último teve como proposta o combate ao racismo, a 
No cenário da promulgação da Carta Constitucional de 1988, o Estado assume outro perfil no contexto nacional, o Estado Democrático de Direito ${ }^{13}$. Para essa nova perspectiva, a cidadania ganha uma nova feição à medida que só será assegurada com a efetiva participação dos sujeitos sociais na reivindicação de seus direitos. Não é suficiente o Estado dizer o que é bom para os indivíduos ou grupos, mas sim, a garantia dos interesses requeridos por esses sujeitos. É, portanto, nesse panorama, que se destacam as comunidades negras rurais, definindo-se como remanescente de quilombo e requerendo a aplicação da garantia constitucional assegurada no art. 68 do Ato das Disposições Constitucionais Transitórias (ADCT) $)^{14}$.

Segundo esse dispositivo, aos remanescentes de comunidades de quilombos que estejam ocupando as suas terras têm reconhecida a propriedade definitiva, cabendo ao Estado emitir-lhes os respectivos títulos ${ }^{15}$. Na análise desse dispositivo constitucional, percebe-se uma

escravidão e o incentivo ao desenvolvimento político, econômico e cultural da população negra (RIBEIRO, 2010). Na esfera nacional, as reivindicações ganharam corpo na nossa carta cidadã de 1988, bem como no Programa Nacional de Direitos Humanos, que tinha como uma de suas propostas a elaboração de um Plano Nacional de Promoção da Igualdade Racial \ PLANAPIR, elaborado em 2009. Dentre os objetivos desse plano, destaca-se o apoio à instituição do Estatuto da Igualdade Racial, com implantação realizada em julho de 2010, cujas propostas são o combate à discriminação racial e a promoção da igualdade étnica. Nesse último aspecto, essa norma vai prever uma série de benefícios para comunidades quilombolas.

13 As propostas que regiam os modelos anteriores de Estado estavam consubstanciadas, respectivamente, no Estado liberal e Estado de bem-estar social.

$14 \mathrm{O}$ art. 68 do ADCT preceitua que Aos remanescentes das comunidades dos quilombos que estejam ocupando suas terras é reconhecida a propriedade definitiva, devendo o Estado emitir-lhes os títulos respectivosA. O processo de identificação, reconhecimento, delimitação, demarcação e titulação dessas terras é atualmente regulamentado pelo Decreto $n^{\circ} 4.887 / 2003$.

15 O aludido direito não abrange aqueles que, embora por fato alheio à sua vontade, não se encontram na posse de suas terras em face de 
mudança no discurso do Estado, cuja tradição remetia a uma exclusão do direito de acesso à terra pelos negros.

Pela primeira vez na história do Brasil, o Estado reconhece, de forma específica, o negro como detentor de direito à terra. Ocorre que essa mudança produzida no discurso do Estado brasileiro, expressa no art. 68 do ADCT, reconhecendo o direito à terra para os remanescentes de quilombos, foi absorvida e ressignificada pelas Comunidades de Quilombo em todo o país, isso considerando o número representativo de pedidos de certificação dessas comunidades. A Fundação Cultural Palmares ${ }^{16}$, órgão ligado ao Ministério da Cultura, aponta que, até fevereiro de 2020, registraram a presença de $3.432^{17}$ comunidades quilombolas em todo o Brasil. Destas, 2.907 estão certificadas por este órgão público ${ }^{18}$.

atos violentos a exemplo de invasão e expulsão, entre outros fatores, apesar da existência de vozes defendendo a extensão da aplicabilidade do preceito constitucional a esses grupos (LEITE, 2000).

$16 \mathrm{O}$ art. $5^{\circ}$ do Decreto $\mathrm{n}^{\circ}$ 4.887/2003 estabelece que: "Compete ao Ministério da Cultura, por meio da Fundação Cultural Palmares, assistir e acompanhar o Ministério do Desenvolvimento Agrário e o INCRA nas ações de regularização fundiária, para garantir a preservação da identidade cultural dos remanescentes das comunidades dos quilombos, bem como para subsidiar os trabalhos técnicos quando houver contestação ao procedimento de identificação e reconhecimento previsto neste Decreto". A fundação Cultural Palmares foi criada pela Lei 7.668/1988, tendo como finalidade promover a preservação dos valores sociais, culturais e econômicos decorrentes da influência negra na população brasileira. Ela só entra em funcionamento em 10 de janeiro de 1992, quando o seu estatuto é criado por força do Decreto 418/92. Informação acessível em estudo realizado pela Sociedade Brasileira de Direito Público - SBDP sobre o direito à terra das comunidades quilombolas, em atendimento à solicitação da Fundação Cultural Palmares. Informação disponível em: http://www.sbdp.org.br/arquivos/material/432_ comunidades_quilombolas_direito_a_terra.pdf. Acesso em: 22 mar. 2014.

17 Informação disponível em: http://www.palmares.gov.br/ wp-content/uploads/2015/o7/TABELA-DE-CRQ-COMPLETAQUADRO-GERAL-3.pdf. Acesso em: 1 maio 2020.

18 Informação disponível em: http://www.palmares.gov.br/ 
A necessidade de ressignificação pode ser explicada, sobretudo porque, muito embora por quilombolas, entendamos os descendentes de negros africanos que ofereceram resistência ao processo de escravidão no Brasil, e que assim se reconheçam ${ }^{19}$ para esse dispositivo constitucional, a noção de quilombo estava enrijecida, referindo-se apenas aos quilombos constituídos pela reunião de negros fugidos, cuja terra era adquirida através da ocupação. Desse modo, a noção que prevaleceu na elaboração do art. 68 do ADCT era própria da legislação colonial e imperial. Trata-se de uma noção histórica do que seria "Quilombo", cujo estatuto esquece a configuração que esses sujeitos ocupam no presente.

O problema da aplicação desse preceito constitucional não estava centrado na existência desses sujeitos sociais ou mesmo do direito que pleiteiam, mas sim na abrangência da realidade social que esse conceito será capaz de reconhecer (ARRUTI, 2008). Não havia previsão no texto legal de uma definição de quem seriam esses indivíduos, sujeitos ou grupos apontados como "remanescentes de quilombos". Assim, no ano de 1994, reuniu-se, no âmbito da Associação Brasileira de Antropologia - ABA, um grupo ${ }^{20}$ de trabalho para discutir sobre as comunidades negras rurais e elaborar um conceito de remanescente de quilombo que se opusesse a noção de "remanescente" como algo já extinto ou em fase de desaparecimento, e de "quilombo" como unidade igualitária,

wp-content/uploads/2015/07/TABELA-DE-CRQ-COMPLETAQUADRO-COMPARATIVO.pdf. Acesso em: 1 maio 2020.

19 O Decreto 4887/2003 apresenta a definição de Quilombo em consonância com a Convenção 169/89 da OIT, ratificada pelo Brasil no ano de 2002, considerando-os "os grupos étnico-raciais, segundo critérios de autoatribuição, com trajetória histórica própria, dotados de relações territoriais específicas, com presunção de ancestralidade negra relacionada com a resistência à opressão histórica sofrida”. Essa convenção entrou em vigor internacional em agosto de 1991 e no Brasil apenas em julho de 2003.

20 Dentre eles estavam Ilka Boaventura Leite, Eliane Cantarino O’Dwyer, João Pacheco de Oliveira, João Batista Borges Pereira, Lúcia Andrade, Dimas Salustiano da Silva e Neusa Gusmão. 
fechada e coesa. Os antropólogos que participaram do debate propuseram que a dimensão do conceito contemplasse os grupos sociais que almejam a aplicação do direito instituído na Constituição Republicana de 1988 (LEITE, 2000).

Esse grupo produziu um documento estabelecendo os parâmetros a serem seguidos pelos Antropólogos quando estiverem desenvolvendo trabalhos sobre essas comunidades, cujos pontos importantes são destacados por O’Dwyer:

O termo quilombo tem assumido novos significados na literatura especializada e também para os grupos, indivíduos e organizações. Ainda que tenha um conteúdo histórico, o mesmo vem sendo 'ressemantizado' para designar a situação presente dos segmentos negros em diferentes regiões e contexto do Brasil. [...] Contemporaneamente, portanto, o termo quilombo não se refere a resíduos ou resquícios arqueológicos de ocupação temporal ou de comprovação biológica. Também não se trata de grupos isolados ou de uma população estritamente homogênea. Da mesma forma, nem sempre foram constituídos a partir de movimentos insurrecionais ou rebelados mas, sobretudo, consistem em grupos que desenvolveram práticas cotidianas de resistência na manutenção e reprodução de seus modos de vida característicos e na consolidação de um território próprio. [...] No que diz respeito à territorialidade desses grupos, a ocupação da terra não é feita em termos individuais, predominando seu uso comum. A utilização dessas áreas obedece à sazonalização das atividades, sejam agrícolas, extrativistas ou outras, caracterizando diferentes formas de uso e ocupação dos elementos essenciais ao ecossistema, que tomam por base laços de parentesco e vizinhança, assentados em relações de solidariedade e reciprocidade (O'DWYER, 2002, p. 19).

Arruti (2008) nos chama a atenção para a complexidade das categorias operadas sobre o tema quilombo. Se por um lado atribui-se estatuto analítico a uma categoria histórica que é ressemantizada, 
por outro surge a necessidade de se fazer novas ressemantizações, dessa vez voltadas para as categorias locais. Isso porque, na elaboração do conceito, reduz-se sociologicamente uma variedade de categorias locais de uso das terras sobre a mesma categoria sociológica de "uso comum" para depois traduzi-la no termo quilombo. Noutro quadrante, ainda será necessário traduzir as categorias locais de autoatribuição em categoria universal de atribuição político-jurídica. Na concepção desse autor, "o processo de ressemantização encontra-se em aberto, estando o desenho inicialmente proposto no documento da ABA em transformação não apenas em função de novos movimentos analíticos, mas também em função dos avanços do movimento social" (ARRUTI, 2008, p. 342).

É preciso assentar que a pressão do movimento negro, através de mecanismos de representação a exemplo da Comissão Nacional Provisória de Articulação das Comunidades Negras Rurais Quilombolas - CNACNRQ, criada em 1995, exigindo dos órgãos governamentais a aplicação do aludido preceito constitucional, levou agências governamentais, tais como a Fundação Cultural Palmares, o Ministério Público Federal e o Instituto Nacional de Colonização e Reforma Agrária INCRA, a produzirem procedimentos próprios para regulamentar o reconhecimento territorial das "chamadas comunidades negras rurais quilombolas” (ARRUTI, 2008; O’DWYER, 2002). No INCRA, a regulamentação foi feita através da portaria 307/95, posteriormente obstada por força do Decreto Presidencial no 3912/2001.

Somente em 1995, vão surgir dois projetos de lei que propõem a regulamentação do art. 68 do $\mathrm{ADCT}$, ambos propostos por membros do movimento negro. Um dos projetos foi iniciativa da Senadora Benedita da Silva (PT/RJ), ligada ao movimento negro urbano. O outro consistiu em proposta do Deputado Federal Alcides Modesto (PT/ $\mathrm{BA})$, ligado à militância da Comissão Pastoral da Terra (CPT). Os dois projetos iniciais, que tinham como impasse a escolha do órgão estatal responsável pela implementação do dispositivo constitucional, foram unificados e convergiram no Projeto de Lei n. 3207/97. As divergências foram solucionadas a partir da proposta de uma parceria entre o INCRA, que adaptaria as demandas por terras das comunidades 
quilombolas ao procedimento aplicado à reforma agrária e à Fundação Cultural Palmares, que assumiria a responsabilidade pela preservação e resgate cultural dessas comunidades (ARRUTI, 2008).

No ano de 1999, durante a tramitação desse projeto, o governo Fernando Henrique Cardoso emitiu a Medida Provisória no 1911 11, alterando a Lei 9.649/98 - Lei de Organização da Presidência da República e dos Ministérios ${ }^{21}$, inserindo nas atribuições do Ministério da Cultura a competência para acompanhar os pedidos de reconhecimento territorial embasados do art. 68 do ADCT. No mesmo ano, essa competência foi delegada pelo aludido Ministério, através da portaria no 447/1999, à Fundação Cultural Palmares. Essa medida, segundo Arruti (2008), desconsiderou as negociações já realizadas pelo INCRA, CNACNRQ e Fundação Cultural Palmares, cujo consenso atribuiu a repartição de competências pelo processo aos dois primeiros. Um agravante para a implementação dessa política estatal estava na ausência de estrutura para atuação da Fundação Cultural Palmares, que desaguava em duas dificuldades: a ausência de recursos para promover as desapropriações e a inexistência de competência desse órgão para promover o registro do título emitido.

Em setembro de 2001, a Medida Provisória 1911-11/99 foi convertida no Decreto Presidencial n ${ }^{\circ} 3912$, que, acompanhado do parecer 22 da Subchefia para Assuntos Jurídicos da Casa Civil da Presidência da República - SAJ 1490, estabelecia obstáculos à aplicação do mencionado preceito constitucional. Dois fatores para a limitação da garantia legal são apontados por Arruti (2008): o primeiro era o exíguo prazo de

21 A Lei 9.649/98 foi modificada posteriormente pelas Medidas Provisórias 2123-28, de janeiro de 2001 e 2216-37, de agosto de 2001.

22 Esse parecer é fruto de consulta sobre a legitimidade do Ministério do Desenvolvimento Agrário e do Incra para propor desapropriações e reconhecer o domínio das terras das comunidades quilombolas. Informação acessível em estudo realizado pela Sociedade Brasileira de Direito Público - SBDP sobre o direito à terra das comunidades quilombolas, em atendimento a solicitação da Fundação Cultural Palmares. Informação disponível em: http://www.sbdp.org.br/arquivos/material/432_comunidades_ quilombolas_direito_a_terra.pdf. Acesso em: 22 mar. 2014. 
três meses para a propositura de todas as demandas fundiárias, restrito àquele mesmo ano, além da exigência de que a regularização seja posteriormente sujeita à votação por lei especial; o segundo consistia na exigência de que essas comunidades comprovassem uma história de cem anos de posse pacífica da terra.

Prevaleceu, no parecer 1490/2001, da SAJ, o entendimento de que a Constituição Federal teria apenas reconhecido um direito pré-existente das comunidades remanescentes de quilombos, que, através da posse prolongada de forma pacífica, contínua e com a vontade de ser dono, requisitavam quanto às terras que ocupavam desde o período do Império, quando guardavam a condição de agrupamentos de escravos fugidos ${ }^{23}$. Nesse período, ocorreu um retrocesso nas conquistas já implementadas pelo movimento negro, o que vai acentuar-se com o veto presidencial, no ano de 2002, ao Projeto de Lei 3207/97, proposta de segmentos do movimento negro para regularização do art. 68 do $\mathrm{ADCT}$, cuja tramitação havia chegado ao fim no âmbito do Congresso Nacional. Essa fase vai perdurar até agosto de $2003^{24}$, quando, por previsão do Decreto Presidencial 4887, serão retomadas as ações para a regularização fundiária das terras quilombolas. $\mathrm{Na}$ prática, essas

23 Informação acessível em estudo realizado pela Sociedade Brasileira de Direito Público - SBDP sobre o direito à terra das comunidades quilombolas, em atendimento a solicitação da Fundação Cultural Palmares. Informação disponível em: http://www.sbdp.org.br/arquivos/material/432_ comunidades_quilombolas_direito_a_terra.pdf. Acesso em: 22 mar. 2014.

24 Infelizmente a luta do movimento negro, quanto à aplicabilidade do art. 68 do ADCT, não se encerrou aqui. Em 25 de junho de 2004, o Partido da Frente Liberal - PFL, atual DEM, propôs uma Ação Direta de Inconstitucionalidade - ADI 3239, contra o Decreto 4887/2003. O relator da ADI, o Ministro Cezar Peluso, manifestou-se pela inconstitucionalidade do Decreto 3239, contudo defendeu que os efeitos da decisão não devem atingir as comunidades com titulação já emitida. Para o relator da ação, os decretos servem apenas para regulamentar leis, não se estendendo essa permissibilidade à Constituição Federal. A ação teve a sua votação suspensa em face do pedido de vista da Ministra Rosa Weber, que ponderou pela constitucionalidade do Decreto. Em 08 de fevereiro de 2018, o Supremo Tribunal Federal, por maioria de seus membros, julgou improcedente o pedido. 
ações só foram retomadas com a edição das instruções normativas do INCRA, no ano de 2005, obtendo os primeiros resultados em 2006 (ARRUTI, 2008).

Apesar do avanço com a retomada das regularizações, a existência de um número expressivo de normas regulamentando esse processo, associada à mudança constante das mesmas e o número significativo de órgãos envolvidos em sua tramitação, tornam esse percurso longo e cansativo para aqueles que aguardam o seu desfecho. Foi o que aconteceu no processo de reconhecimento da territorialidade da comunidade negra do Jatobá.

\subsection{O Reconhecimento do território do Jatobá}

O processo de reconhecimento do território negro do Jatobá está imerso nesse novo momento, após o Decreto 4887/2003, em que se tornaram recorrentes demandas fundiárias das comunidades negras rurais em todo o Brasil, reivindicando a identificação, demarcação e titulação coletiva de seus territórios. No estado do Rio Grande do Norte, vinte comunidades negras abriram processos de regularização fundiária junto ao INCRA. Segundo a ordem cronológica de abertura dos processos, observa-se a seguinte lista ${ }^{25}$ : Boa Vista dos Negros (Parelhas), Acauã (Poço Branco), Capoeira (Macaíba), Jatobá (Patu), Sibaúma (Tibau do Sul), Aroeiras (Pedro Avelino), Macambira (Lagoa Nova), sítio Grossos (Bom Jesus), Nova Descoberta (Ielmo Marinho), Sítio Pavilhão (Bom Jesus), Picadas (Ipanguaçu), Bela Vista Piató (Assú), Sítio Pega (Portalegre), Sítio Moita Verde (Parnamirim), Sítio Sobrado (Lages), Sítio Arrojado (Portalegre), Sítio Lages (Portalegre), Gameleira de Baixo (São Tomé), Geral (Touros) e Negros do Riacho (Currais Novos).

Dentre essas, destacaram-se, no andamento dos processos, as comunidades do Jatobá (Patu), Acauã (Poço Branco) e Boa Vista dos Negros

25 Informação disponível em: http://www.incra.gov.br/sites/default/files/ incra-processosabertos-quilombolas-v2.pdf. Acesso em: 23 jul. 2018. 
(Parelhas). Entre essas, a comunidade do Jatobá foi a primeira a receber a titulação coletiva de suas terras, muito embora tenha sido concedida em caráter parcial. ${ }^{26}$ Em 2015, o processo chega à conclusão, ficando como pendência a união das matrículas dos oito títulos em um só. ${ }^{27}$

$\mathrm{Na}$ fala de uma das lideranças políticas da comunidade sobre esse processo, Sandra da Silva, encontramos a presença do movimento negro do Rio Grande do Norte, que, através da ONG Kilombo Organização Negra do RN, acompanhada de um grupo de angolanos, no ano de 2001, tomaram conhecimento de que eles constituíam uma comunidade quilombola. Após a presença da ONG Kilombo, foram inseridos nos encontros organizados por essa entidade, quando receberam orientações sobre seus direitos. Foi na conversa com os visitantes que a comunidade tomou conhecimento da existência de uma regulamentação legal sobre as comunidades quilombolas e que estavam perdendo direitos.

Foi de 2001 para cá que eu vim despertar como quilombo. A visita do pessoal de Angola que veio, foi isso que veio me despertar e falou para nós sobre a lei e que lei foi essa que ele falou que veio me despertar o que é quilombola, ah, nós estamos perdendo é coisa aqui (S.S., COMUNIDADE NEGRA DO JATOBÁ, 2014).

Embora os primeiros contatos com a ONG Kilombo tenham ocorrido no ano de 2001, os negros residentes naquela comunidade rural, somente no ano de 2004, vão pleitear, junto ao INCRA, o reconhecimento das terras que ocupam, correspondentes a uma área física de

26 No intuito de agilizar o processo, no mês de novembro de 2014, o INCRA concedeu a titulação coletiva das terras cujos processos de desapropriação foram concluídos, bem como daquelas sobre as quais não restavam divergências.

27 Informação disponível em: http://www.incra.gov.br/noticias/ incra-avanca-na-regularizacao-de-tres-territorios-quilombolasno-rio-grande-do-norte. Acesso em: 23 jul. 2018. 
81,5256 hectares, adquirida através de contrato de compra e venda ${ }^{28}$. Essa demora pode ser explicada em face dos entraves opostos pelo Governo brasileiro, entre os anos 2000 e 2003, aos pedidos de reconhecimento dessas comunidades.

No caso do Jatobá, também foi requisitada, no laudo de identificação e delimitação do território, a incorporação, através da aquisição, de uma área de 137,6678 hectares, pertencente a vizinhos confinantes, cuja justificativa, apontada pelo antropólogo responsável pelo laudo, Luiz Assunção ${ }^{29}$, enfatiza a necessidade de áreas para a reprodução física, econômica e cultural da própria comunidade. O Decreto 4887/2003, assim como a instrução normativa $n^{\circ} 20$ do INCRA ${ }^{30}$, autoriza esse procedimento, em se tratando de medida necessária para garantir a existência do grupo. A decisão pela autoatribuição "quilombola" e titulação coletiva das terras foi coletiva, tomada em reunião para esse fim, no mês de agosto do ano de 2004.

28 A forma de constituição dos quilombos que prevalece no imaginário popular é a ocupação, contudo o surgimento dessas comunidades pode ser atribuída a outras origens, a exemplo da doação, herança e compra e venda. Isso é fruto da noção de quilombo que se disseminou no Estado Brasileiro nos períodos colonial e imperial, associando essa formação à ocupação de terras por negros fugidos. Trata-se de conceito formulado pelo Conselho Ultramarino Português, em 1740.

29 Professor do departamento de Antropologia e dos programas de pós-graduação da Universidade Federal do Rio Grande do Norte - UFRN. A sua atuação deve-se à parceria firmada entre o Incra/RN e a UFRN, através do Projeto Quilombolas. Essa parceria é autorizada no art. $3^{\circ}$ do Decreto 4.887/2003.

30 Art. $4^{\circ}$ Consideram-se terras ocupadas por remanescentes das comunidades de quilombos toda a terra utilizada para a garantia de sua reprodução física, social, econômica e cultural, bem como as áreas detentoras de recursos ambientais necessários à preservação dos seus costumes, tradições, cultura e lazer, englobando os espaços de moradia e, inclusive, os espaços destinados aos cultos religiosos e os sítios que contenham reminiscências históricas dos antigos quilombos. 
Tudo que a gente vai fazer é em reunião, se reunimos e levei a proposta, lembro que veio uma pessoa de lá e explicou tudo. Como é o processo do INCRA e o pessoal abordaram o projeto. Já tinha a associação. A associação foi fundada [...], fundada em que, meu Deus? meu Deus! meu Deus!, meu Deus! Me fugiu a mente agora, mas lembro que já tinha a associação. Quando eles vieram precisou do [...] quando eles vieram fazer a reunião já tinha a ata registrada (S.S., COMUNIDADE QUILOMBOLA DO JATOBÁ, 2014).

Essa opção, contudo, comporta alguns desdobramentos, de ordem social e jurídica, que merecem ser considerados. Ao decidirem pela titulação coletiva, os moradores que eram proprietários das terras da comunidade renunciam ao domínio privado das mesmas em benefício de uma propriedade coletiva, de uso comum para todos. Ou seja, com essa nova modalidade jurídica de domínio, todas as decisões relativas ao uso das terras (organização das residências, plantio etc.), antes resolvidas individualmente e dentro de uma respectiva família, agora são deliberadas em coletivo, ouvindo-se toda a comunidade. Outro ponto determinante dessa mudança é a impossibilidade de alienação dessas terras, que com a titulação coletiva, passam a pertencer a todos os quilombolas daquele grupo.

Nesse processo, uma indagação acomete as mentes mais curiosas: quais motivos foram determinantes para assunção da identidade quilombola pela comunidade negra do Jatobá? Sandra da Silva responde a essa inquietação quando indagada sobre os benefícios que a comunidade auferiu com a iniciativa da titulação coletiva:

Eu acho esse processo e esse projeto [...] eu aprovo ele né. Por quê? Porque a partir de agora [...] ontem um quilombola brincava e dizia assim: ah eu vou vender minha terra e vou embora daqui. Aí eu disse assim: pois eu vou oferecer minha terra (risos). Por quê? Porque essa terra vai ficar para neto e bisneto né. É um espaço [...] Antes nós tínhamos só oitenta e poucos hectares para trinta pessoas e hoje nós temos duzentos e poucos hectares. Eu 
digo: olhe vocês tem terra aí para saber o que vocês vão fazer com elas. Então pra mim eu acho esse projeto muito importante (S.S., COMUNIDADE QUILOMBOLA DO JATOBÁ, 2014).

Essa vontade de manter as terras na posse da comunidade também é manifestada na fala de seu José Luiz de Aquino, um dos sete filhos do casal João Luiz de Aquino e Maria Juliana de Aquino, primeiros proprietários do Jatobá, como sendo a continuidade da vontade de seu pai: "Eu quero, do jeito que ele pretendia morrer e deixar pra mim eu pretendo morrer e deixar pra eles também. Era meu prazer era esse. Aí eu fui lá me entender com minhas tias, meus tios, aí eles me explicaram, papai tinha aceitado, aí eu disse, tá bom." (J. L. A., COMUNIDADE QUILOMBOLA DO JATOBÁ, 2014);

Tais falas nos faz assentar que a busca pela titulação coletiva do território negro do Jatobá consiste na possibilidade de reaver as terras que antes incorporavam o seu território e que se encontravam no domínio de proprietários vizinhos, embora através da aquisição legal de compra e venda. É, portanto, uma forma que a comunidade encontrou de evitar desmembramentos das terras em face da venda por seus moradores, além de garantir a manutenção do livre exercício de suas práticas, crenças e valores considerados em sua especificidade. Essa decisão consistiu, ainda, numa forma da comunidade se afirmar, saindo do esquecimento e marginalidade junto aos entes estatais e outros grupos étnicos com quem se relacionam, além de consistir numa estratégia para manutenção de sua cultura.

\subsection{Algumas considerações}

O processo de reconhecimento do território negro do Jatobá está imerso num contexto, após 1988, em que se tornaram recorrentes demandas fundiárias das comunidades negras rurais em todo o Brasil. Trata-se da reivindicação da implementação do art. 68 do ADCT, que assegura aos remanescentes das comunidades de quilombos a propriedade definitiva das terras que ocupam. 
Essas demandas passaram a ocupar um lugar específico na agenda do movimento negro, destacando-se, nessa conjuntura, como forma de organização e mobilização política, o movimento quilombola, cuja reivindicação centra-se na questão fundiária. Trata-se de uma organização em que as suas discussões se voltam para a questão do direito à terra do negro residente em comunidades rurais. Isso não quer dizer que não haja uma demanda em comum com o movimento negro urbano, pois ambos buscam a superação da desigualdade racial no Brasil. A causa negra apresenta-se, portanto, como o ponto convergente das duas agendas, que é a luta pela igualdade de direitos.

A atuação do movimento negro, nesse processo de implementação do dispositivo constitucional, ganha relevância sob três prismas: encontrar um conceito de quilombo que atenda a realidade das comunidades negras rurais do Brasil; pressionar os entes e órgãos do governo a darem aplicabilidade ao direito assegurado constitucionalmente; e orientar esses grupos quanto à reivindicação de seus direitos. Muito embora o movimento negro, sobretudo o quilombola, tenha avançado quanto ao reconhecimento formal de direitos, no plano material essas conquistas ainda se apresentam longe do ideal. No caso das comunidades negras rurais, essa realidade pode ser percebida quando analisado o número de comunidades efetivamente tituladas, a resistência ao reconhecimento desse direito e a necessidade de as comunidades quilombolas buscarem apoio junto a órgãos internacionais.

Segundo dados recolhidos do Guia de Políticas Públicas para Comunidades Quilombolas ${ }^{31}$, do Programa Brasil Quilombolas, organizado pela Secretaria de Políticas de Promoção da Igualdade Racial - SEPPIR, no ano de 2013, de 2040 comunidades certificadas pela Fundação Cultural Palmares, 1229 estão com processo de titulação aberto junto ao INCRA, tendo apenas 207 comunidades adquirido a titulação coletiva de suas terras.

31 Informação disponível em: http://www.seppir.gov.br/ portal-antigo/arquivos-pdf/guia-de-acesso-a-politicaspublicas-do-pbq. Acesso em: 16 ago. 2018. 
A resistência ao reconhecimento do direito dessas comunidades pode ser aferida nos inúmeros entraves legais, financeiros e jurídicos ao regular andamento dos processos, a exemplo das mudanças na atribuição de competência do órgão executor do processo de titulação coletiva; das modificações no procedimento e direitos realizados através de leis, portarias e instruções normativas; dos escassos recursos destinados à regularização fundiária desses grupos; além da tentativa de invalidação judicial do Decreto Presidencial n 4887, de 2003, através da propositura da ADI 3239 no ano de 2004.

Em 2017, várias organizações da sociedade civil ${ }^{32}$ fizeram nova denúncia junto à Comissão Interamericana de Direitos Humanos ${ }^{33}$, relatando a situação precária das titulações coletivas das comunidades quilombolas no Brasil. Percebe-se, portanto, que a luta do movimento negro por direitos sociais e igualdade é um movimento constante.

32 Entre elas a Coordenação Nacional das Comunidades Negras Rurais Quilombolas - CONAQ, a Terra de Direitos e a Comissão Pastoral da Terra Nordeste II.

33 Informação disponível em: http://terradedireitos.org.br/noticias/ noticias/estado-brasileiro-sera-questionado-na-cidh-por-morosidadena-titulacao-de-terras-quilombolas/22655. Acesso em: 16 ago. 2018. 
- SOCIEDADE E CULTURA NO RIO GRANDE DO NORTE - 


\title{
REFERÊNCIAS
}

\author{
ALBERTI, V.; PEREIRA, A. A. (org). Histórias do movimento \\ negro no Brasil: depoimentos ao CPDOC. Rio de Janeiro: Pallas; \\ CPDOC-FGV, 2007.
}

ARRUTI, J. M. Quilombos. In: PINHO, O. A.; SANSONE, L. (org.) Raça: novas perspectivas antropológicas. Salvador: Associação Brasileira de Antropologia; EDUFBA, 2008.

BRASIL. Constituição, Código Civil, Código de Processo Civil e legislação correlata. In: VADE mecum acadêmico-forense: legislação federal. São Paulo: Revista dos Tribunais, 2005.

BRASIL. Lei $\mathrm{n}^{\circ}$ 9.649, de 27 de maio de 1998. Dispõe sobre a organização da Presidência da República e dos Ministérios, e dá outras providências. Diário Oficial da União, Brasília, DF, 27 maio 1998. Disponível em: https://bit.ly/3eNEnxe. Acesso em 16 ago. 2018.

BRASIL. Casa Civil. Decreto n 4.887, de 20 de novembro de 2003. Regulamenta o procedimento para identificação, delimitação, demarcação e titulação das terras ocupadas por remanescentes das comunidades dos quilombos de que trata o art. 68 do Ato das Disposições Constitucionais Transitórias. Diário Oficial da União, Brasília, DF, 20 nov. 2003. Disponível em: https://bit.ly/2WYish1. Acesso em: 24 abr. 2014. 
BRASIL. Presidência da República. Decreto n 3912, de 10 de setembro de 2001. (Revogado pelo Decreto $n^{\circ} 4.887$, de 20 nov. 2013). Regulamenta as disposições relativas ao processo administrativo para identificação dos remanescentes das comunidades dos quilombos e para o reconhecimento, a delimitação, a demarcação, a titulação e o registro imobiliário das terras por eles ocupadas. Brasília, DF, 11 set. 2001. Disponível em: http://www.planalto.gov.br/ ccivil_03/Decreto/2001/D3912.htm. Acesso em: 23 jul. 2020

\section{BRASIL. Ministério da Cultura. Portaria no 447 de 02 de}

dezembro de 1999. Delega competência à titular da Presidência da Fundação Cultural Palmares. Brasília: Ministério da Cultura, 1999. Disponível em: https://bit.ly/2WGVpqM. Acesso em: 16 ago. 2018.

LEITE, I. B. Os Quilombos no Brasil: questões conceituais e normativas. Etnográfica, v. 4, p. 333-354, 2000.

O’DWYER, E. C. Os quilombos e a prática profissional do antropólogo. In: O’DWYER, E. C. (org.). Quilombos, identidade étnica e territorialidade. Rio de Janeiro: FGV; ABA, 2002, p. 13-43.

QUADRO geral de comunidades remanescentes. Brasília: Fundação Cultural Palmares, 2018. Disponível em: http://www.palmares.gov. br/wp-content/uploads/2015/07/TABELA-DE-CRQ-COMPLETAQUADRO-GERAL-3. pdf. Acesso em: 23 jul. 2020.

QUILOMBOLAS: relator vota pela inconstitucionalidade do decreto 4887/2003. Brasília: STF, 2012. Disponível em: https://bit.ly/2WIm32j. Acesso em: 21 jul. 2020.

RAFFESTIN, C. Por uma geografia do poder. São Paulo: Ática, 1993. 
RIBEIRO, M. O enlace entre direitos humanos, superação do racismo e a discriminação racial. In. VENTURI, G. (org.). Direitos humanos: percepções da opinião pública: análises de pesquisa nacional. Brasília: Secretaria de Direitos Humanos, 2010. p. 143-154.

BRASIL. Secretaria de Políticas de Promoção da Igualdade Racial. Guia de Políticas Públicas para Comunidades Quilombolas. Brasília: SEPPIR, 2013. Programa Brasil Quilombola. Disponível em: https://bit.ly/3fPsrfJ. Acesso em: 16 ago. 2018.

SBDP-SOCIEDADE BRASILEIRA DE DIREITO PÚBLICO. O Direito à terra das comunidades remanescentes de quilombos: artigo 68 do Ato das Disposições Constitucionais Transitórias. São Paulo: SBDP, 2002. Disponível em: https://bit.ly/2OM6zpD. Acesso em: 22 mar. 2018 